\title{
Receptionist rECognition and rEferral of PaTients with Stroke (RECEPTS) study - protocol of a mixed methods study
}

\author{
James P Sheppard ${ }^{1}$, Satinder Singh ${ }^{2}$, Janet Jones ${ }^{3}$, Elizabeth Bates ${ }^{3 *}$, John Skelton ${ }^{3}$, Connie Wiskin ${ }^{3}$,
}

Richard J McManus ${ }^{1}$ and Ruth M Mellor ${ }^{3}$

\begin{abstract}
Background: As the first point of contact for patients and witnesses of stroke, General Practice receptionists can be instrumental in deciding the urgency of clinical contact. Despite the considerable complexity of this task, reception staff are not clinically trained. Minimising the time taken to access thrombolysis is crucial in acute stroke as treatment must be initiated within 4.5 hours of the onset, and the earlier the better, to achieve the best outcomes. Research suggests that patients who first contact their General Practice following the onset of stroke symptoms are less likely to receive thrombolysis, in part due to significant delays within Primary Care.

This study therefore aims to understand the role of General Practice receptionists, with particular interest in receptionist's ability to recognise people who may be suffering from a stroke and to handle such patients as a medical emergency.
\end{abstract}

Methods: The Receptionist rECognition and rEferral of PaTients with Stroke (RECEPTS) study will be a Primary Care based mixed methods study. 60 General Practices in the West Midlands will be recruited. Each practice will receive 10 unannounced simulated patient telephone calls, after the 10 calls questionnaires will be administered to each receptionist. These will examine the behaviour of receptionists towards patients presenting in Primary Care with stroke symptoms, and their knowledge of stroke symptoms. An embedded qualitative study will use interviews and focus groups to investigate the views of General Practice staff on the receptionists' role in patient referral and whether training in this area would be helpful.

Discussion: The results of the RECEPTS study will have important implications for providers of Primary Care. The study will establish current practice in UK primary care in terms of General Practice receptionists' knowledge of the presentation and appropriate referral of those who may be suffering a stroke. It will highlight training needs and how such training might be best delivered.

Keywords: Medical receptionists, General Practice, Family practice, Health Services Administration, Simulation, Patient, Research, Qualitative, Questionnaires

\section{Background}

In the UK, as in similar contexts, General Practice (GP) receptionists operate in the interface between patients and their doctors. They are usually the first person a patient, spouse or other witness of an event, speaks to when contacting their GP and they are instrumental in deciding on the urgency of clinical contact and when (or

\footnotetext{
*Correspondence: e.j.bates@bham.ac.uk

${ }^{3}$ Primary Care Clinical Sciences, University of Birmingham, Birmingham, UK Full list of author information is available at the end of the article
}

if) an appointment will be made [1,2]. As such they have an important gate-keeping role [3] and are influential in the facilitation of the patient journey.

Despite being integral members of the Primary Care Team, GP reception staff may be minimally trained, often learning about their role from other receptionists while on-the-job [4]. This may impair the ability of reception staff to correctly identify the level of urgency required from patients seeking access to healthcare which is increasingly important as new acute treatments 
are developed in a range of different illnesses. The need for appropriate training has been consistently recognised by researchers, doctors and reception staff themselves [5-7].

In the UK, there are 152,000 new stroke cases every year [8]. The direct economic costs to the NHS are considerable, accounting for approximately $5 \%$ of total UK NHS costs or $£ 4$ billion [9]. The burden of stroke can be considerably reduced if patients are rapidly thombolysed following the onset of symptoms by specialists in secondary care [10], as soon as possible after symptom onset [11], and within the 4.5 hours 'therapeutic window' [12-14]. Yet only 4-5\% of patients with stroke receive thrombolysis in developed countries [15,16]. A significant barrier to thrombolysis is the time delay between patients experiencing symptoms of a stroke, contacting healthcare services [17] and correctly being identified and treated by healthcare staff [18]. Fewer than half patients reported recognising their own stroke [19] and members of the public vary greatly in the their knowledge of stroke symptoms [20]. Patients and bystanders help seeking behaviour can be influenced by perception of the severity of the symptoms [21-23], how they fitted the symptoms into their normal life [23], the influence of others $[21,23]$ and concern around the consequences of contacting medical services [22].

Previous studies suggest that contacting the GP following the onset of stroke symptoms is one such cause of thrombolysis time delay [24]. Indeed, it is estimated that only $55-71 \%$ of patients who call their GP with symptoms of stroke are correctly referred on to the emergency services [24,25]. However, these existing studies are limited due to small sample sizes and the methodology used to obtain these estimates.

\section{Study aims}

This study aims to:

1. Assess receptionists' ability to direct patients with, or witnesses of, stroke symptoms for emergency care, and their knowledge of stroke symptoms.
2. Investigate the views of Primary Care staff on the receptionists' role in relation to patient access to emergency care.

\section{Methods}

\section{Study design}

The project will be a Primary Care based mixed methods study. Assessment will be carried out using unannounced simulated patient telephone calls, questionnaires, an answerphone assessment and qualitative interviews and focus groups; the setting and data collected by these methods is summarised in Table 1 . The sequence of these methods is outlined in Figure 1. Unannounced simulated patient telephone calls and answerphone assessments will be conducted prior to receptionists receiving questionnaires or invitations to participate in a focus group. Non-reception GP staff can be invited for interview at any point in the study, as their involvement in an interview should not influence simulated call results.

\section{Study population}

The population of interest are reception staff based in collaborating GPs in NHS Primary Care Providers within Birmingham and Solihull, West Midlands, UK. All practices within this region will be invited to participate and those agreeing will provide written practice level consent, from both a General Practitioner and the Practice Manager (or equivalent). Receptionists within participating practices will be informed about the study by the Practice Manager but they will not be told the calls will be specifically about stroke. For the questionnaires, consent will be assumed by their completion. Separate individual written consent will be obtained for those taking part in interviews and focus groups.

All participating practices will be reimbursed for any additional work required to participate in the study.

Unannounced simulated patient telephone calls

Medical role players will make telephone calls to GPs using vignettes of patients experiencing stroke-like symptoms to

Table 1 Summary of RECEPTS methods, setting and data collected

\begin{tabular}{|c|c|c|}
\hline Setting & Method & Data collected \\
\hline UoB (telephone call to General Practice) & Unannounced simulated patient telephone call & Receptionists response to stroke symptoms \\
\hline UoB (telephone call to General Practice) & Voice recording & Record the General Practice out-of-hours message \\
\hline \multirow[t]{2}{*}{ General Practice } & Questionnaire (anonymous) & Receptionist demographic data. \\
\hline & & $\begin{array}{l}\text { Receptionist knowledge and planned response to } \\
\text { stroke and a variety of other symptoms }\end{array}$ \\
\hline General Practice & Focus Groups & $\begin{array}{l}\text { Receptionist views on their role in the triage of } \\
\text { patients and their views on training for receptionists }\end{array}$ \\
\hline General Practice & Interviews & $\begin{array}{l}\text { The views of other Primary Care staff on the role, skills } \\
\text { and potential of reception staff }\end{array}$ \\
\hline
\end{tabular}




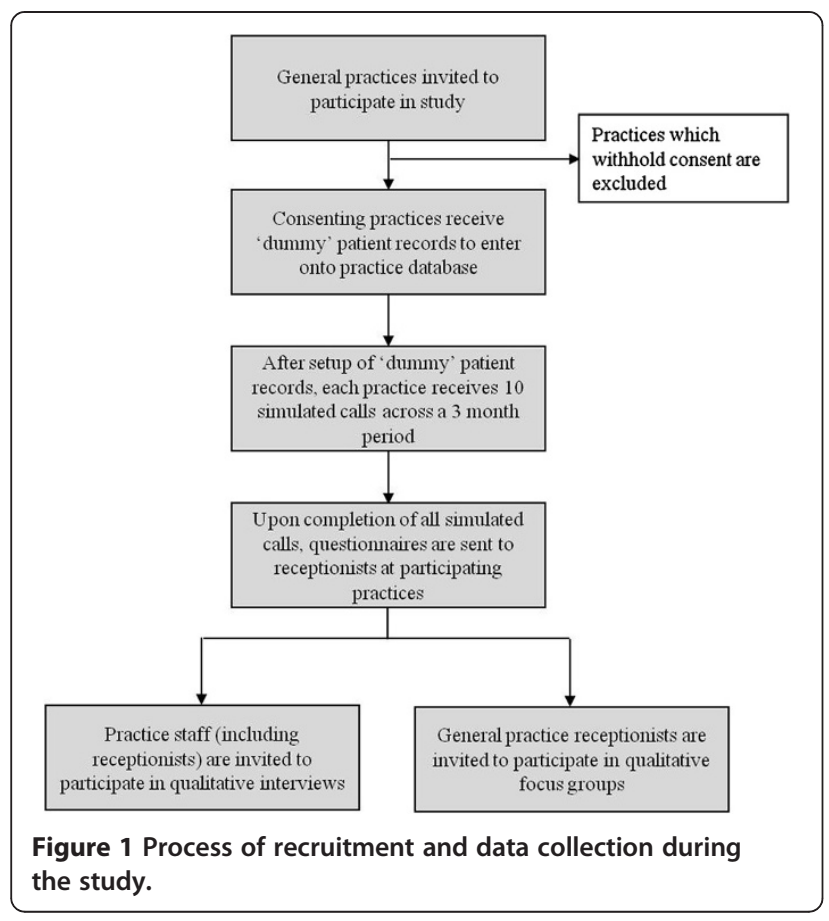

guide their performance. Simulated patient scenarios are an accepted methodology for assessing clinical performance, particularly in Primary Care [26,27]. This methodology has been used for a variety of clinical performance evaluation studies [28-30] including telephone triage of chest pain patients for immediate hospital care [31,32]. However, despite the context, content and face validity of unannounced simulated patient telephone calls in Primary Care, its use among GP reception staff is novel and untested in the literature. The Interactive Studies Unit (at the University of Birmingham) has successfully supported medical receptionist training for a number of years. Role players taking part in the study will all be members of the Interactive Studies Unit trained specifically for teaching, research and assessment purposes in a medical education context.

Ten unannounced simulated patient telephone calls made during the normal working day will be conducted at each practice over a three month period. Ten different stroke vignettes will be delivered, designed to represent the wide range of presentations of stroke that could be encountered by reception staff in Primary Care. The vignettes were designed by the team, including two General Practitioners for clinical input, stroke patient representatives were consulted regarding specific phrasing of the vignettes and role players reviewed the vignettes for practical use. The vignettes varied systematically: ranging from straight-forward classical presentations of anterior circulation stroke to more subtle symptoms suggestive of specific types of anterior or posterior circulation stroke; who observed the symptoms; and suspicion of the caller, in two vignettes they state thinking the patient was experiencing a stroke. Ease of recognition of vignettes was categorised by an expert panel consisting of five clinicians, two stroke survivors and six receptionists (not otherwise involved in the study). Role players will present vignettes either as the patient experiencing the symptoms or a relative (witness) calling to seek advice (Table 2).

Each role-player will be provided with detailed information regarding the context of each vignette and will be representative of the local population. In each vignette, the patient will only have had symptoms for 2 hours, therefore being eligible for thrombolysis but warranting immediate assessment by a specialist in order to remain within the optimum time period for such treatment. Dummy patient medical records will be generated for each simulated patient and these will be entered onto the clinical computer system of each participating practice by Practice Managers in order to minimise the potential for receptionist recognition of the unannounced simulated patient telephone call. It will not be possible to provide scripts for the role players as each call will be unique and dependent on receptionist responses. However, each telephone call will end with the role-player thanking the receptionist and informing them that the call was part of the RECEPTS study and that no further action is required.

The unannounced simulated patient telephone calls will be recorded for audit purposes although practices will have the option to opt out of recording. Recorded encounters may subsequently be used for linguistic analysis and the improvement of receptionist training. GP receptionist responses will be coded using an unannounced simulated patient telephone call data collection sheet, containing anticipated responses to the unannounced simulated patient telephone call (see Additional file 1).

The unannounced simulated patient telephone calls will be piloted in two practices prior to roll out, and findings will be integrated into the main study design. The aims of the pilot will be to: 1) assess the feasibility of generating simulated patient records within the practice computer system; 2) trial vignettes, each practice will receive five calls each, so that all ten vignettes will be trailed; 3) pilot the unannounced simulated patient telephone call data collection sheet; and 4) assess the systems for preventing potential adverse events, such as inappropriate engagement with Emergency Medical Services.

\section{Questionnaires}

To assess knowledge and planned responses to stroke symptoms, reception staff from all practices within the study will receive a questionnaire, after the unannounced simulated patient telephone calls have been conducted at 
Table 2 Vignette content

\begin{tabular}{|c|c|c|c|c|c|}
\hline ID & $\begin{array}{l}\text { Brain territory } \\
\text { of stroke }\end{array}$ & $\begin{array}{l}\text { Who } \\
\text { called }\end{array}$ & Vignette details* & Symptoms (no. FAST symptoms) & 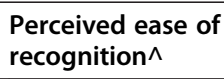 \\
\hline \multirow[t]{4}{*}{1} & \multirow[t]{4}{*}{ Anterior } & \multirow[t]{4}{*}{ Adult child } & I think my Mom's having a stroke: & \multirow{4}{*}{$\begin{array}{l}\text { Facial droop (right side), right arm weakness and } \\
\text { speech disturbance (3 FAST symptoms) }\end{array}$} & \multirow[t]{4}{*}{ Easy } \\
\hline & & & - Her mouth is drooping & & \\
\hline & & & - Her speech is slurred & & \\
\hline & & & - She can't use her right arm & & \\
\hline \multirow[t]{2}{*}{2} & \multirow[t]{2}{*}{ Anterior } & \multirow[t]{2}{*}{ Patient } & I think I need to see the Doctor: & \multirow[t]{2}{*}{ Arm weakness (1 FAST symptom) } & \multirow[t]{2}{*}{ Difficult } \\
\hline & & & - My arm's gone all weak & & \\
\hline \multirow[t]{4}{*}{3} & \multirow[t]{4}{*}{ Posterior } & \multirow[t]{4}{*}{ Patient } & I don't know what to do: & \multirow{4}{*}{$\begin{array}{l}\text { Vomiting, vertigo and visual field defect } \\
\text { (0 FAST symptoms) }\end{array}$} & \multirow[t]{4}{*}{ Difficult } \\
\hline & & & . I keep throwing up & & \\
\hline & & & - I'm feverish & & \\
\hline & & & - I have double vision & & \\
\hline \multirow[t]{2}{*}{4} & \multirow[t]{2}{*}{ Anterior } & \multirow[t]{2}{*}{ Patient } & I'm not sure what to do: & \multirow[t]{2}{*}{ Facial droop (left side) (1 FAST symptom) } & \multirow[t]{2}{*}{ Moderately easy } \\
\hline & & & $\begin{array}{l}\text { - When I look in the mirror my } \\
\text { reflection looks funny }\end{array}$ & & \\
\hline \multirow[t]{4}{*}{5} & \multirow[t]{4}{*}{ Posterior } & \multirow[t]{4}{*}{ Patient } & $\begin{array}{l}\text { What shall I do I think I'm having a } \\
\text { stroke? }\end{array}$ & \multirow[t]{4}{*}{$\begin{array}{l}\text { Vomiting, vertigo and visual field defect } \\
\text { (0 FAST symptoms) }\end{array}$} & \multirow[t]{4}{*}{ Difficult } \\
\hline & & & - I've thrown up & & \\
\hline & & & - The room is spinning & & \\
\hline & & & - I have double vision & & \\
\hline \multirow[t]{3}{*}{6} & \multirow[t]{3}{*}{ Anterior } & \multirow[t]{3}{*}{ Adult child } & $\begin{array}{l}\text { Do you think my Father needs to } \\
\text { see the Doctor? }\end{array}$ & \multirow[t]{3}{*}{$\begin{array}{l}\text { Right arm weakness and speech disturbance } \\
\text { (2 FAST symptoms) }\end{array}$} & \multirow[t]{3}{*}{ Easy } \\
\hline & & & • He's having difficulty speaking & & \\
\hline & & & • He can't lift his arm up & & \\
\hline 7 & Anterior & Patient & $\begin{array}{l}\text { I think I need to see the Doctor my } \\
\text { Daughter tells me that: }\end{array}$ & $\begin{array}{l}\text { Facial droop (left side) and arm weakness } \\
\text { (2 FAST symptoms) }\end{array}$ & Moderately easy \\
\hline & & & - My face is all droopy (left side) & & \\
\hline & & & - I keep dropping things & & \\
\hline 8 & Anterior & Adult child & $\begin{array}{l}\text { Can I make an appointment for my } \\
\text { Father? }\end{array}$ & $\begin{array}{l}\text { Facial droop (right side) and speech disturbance } \\
\text { (2 FAST symptoms) }\end{array}$ & Easy \\
\hline & & & • His face is all lopsided (right side) & & \\
\hline & & & - He's having trouble speaking & & \\
\hline 9 & Anterior & Adult child & $\begin{array}{l}\text { I think my Mom needs to see the } \\
\text { Doctor: }\end{array}$ & Speech disturbance (1 FAST symptom) & Moderately easy \\
\hline & & & - Her speech is all slurred & & \\
\hline 10 & Anterior & Adult child & $\begin{array}{l}\text { Shall I bring my Mother in to see } \\
\text { the Doctor? }\end{array}$ & $\begin{array}{l}\text { Facial droop (right side), right arm weakness and } \\
\text { speech disturbance ( } 3 \text { FAST symptoms) }\end{array}$ & Easy \\
\hline & & & - She can't use her right arm & & \\
\hline & & & - She keeps dropping things & & \\
\hline & & & - Her face is really funny (right side) & & \\
\hline & & & - She's talking a load of rubbish & & \\
\hline
\end{tabular}

*If probed, symptoms were described as being ongoing and of having had a sudden onset within two hours of the telephone call.

$\wedge$ Probability of recognising symptoms was defined by an expert panel consisting of 5 clinicians, 6 receptionists (not otherwise involved in the study) and 2 stroke survivors.

the practice. Questionnaires are commonly used to assess knowledge of stroke symptoms amongst patients and members of the public [33-37] and these will be adapted for use in this study. The questionnaire will gather reception staff demographic details, personal experience of stroke, job experience, training to recognise stroke, understanding of stroke symptoms and planned responses to a variety of symptoms, including some that are not normally associated with stroke. Questionnaires will be anonymous: a study ID which codes by GP will be 
recorded but not receptionist name. The validity of the questionnaire used in the present study will be assessed by piloting with a group of receptionists from one practice and follow up with a focus group to discuss interpretations of each question.

The effectiveness of the questionnaire at distinguishing between high and low levels of knowledge of stroke symptoms/responses will be assessed by comparing the questionnaire responses of healthcare professionals with differing levels of clinical training (receptionists, practice nurses and GPs). We will also examine the questionnaire responses of receptionists before and after a training session on stroke symptoms/responses to assess how effective it is at detecting changes in the stroke knowledge of participants from the target population. The results from individuals participating in the pilot will not be used in the main analysis.

\section{Answerphone message assessment}

An assessment of GP answerphone messages will be carried out. Out of hours messages will be recorded and dialogue examined to see whether messages direct patients with specific symptoms to access other healthcare services, for example do they tell people with stroke symptoms to call the Emergency Medical Services.

\section{Qualitative}

Qualitative methodology will be used to access study participants perceptions, understanding and attitudes towards handling stroke patients and GP receptionist training. The role of Primary Care reception staff in the referral of patients requiring urgent clinical intervention is currently poorly described; qualitative methods are especially applicable where a deeper understanding of contexts, interactions and processes is required to aid implementation of policy. Novel data will be generated about:

1) The views of Primary Care staff on the roles, skills and potential of reception staff with a particular focus on referral of patients.

2) Primary Care staffs' awareness, understanding and experience of referral of patients by reception staff.

3) Opportunities for and barriers to effective referral of patients by reception staff and the Primary Care team.

4) Approaches and attitudes toward development of the role of reception staff within Primary Care.

5) Primary Care staffs' perception of the training needs of reception staff and requirements to develop role in stroke patient referral.

Focus groups and interviews will be conducted in a setting determined by participant preference at a convenient location and time for participants and their Primary Care practice. All participants will give written informed consent. Sampling will be purposive to identify participants' representative of a range of Primary Care staff, seniority and experience, practice size and location. Focus groups will be delineated by participants' role. This approach will allow us to develop an explanation of the study objectives that encompasses the range of environments in which Primary Care is delivered.

Topic guides for in-depth interviews and focus groups will be informed by existing literature and simulated call results. It will be iteratively modified in response to emergent data as the study progresses. Topic guides will be discussed with and informed by the GP receptionist representative on the study steering group. All interviews and focus groups will be recorded, transcribed and checked for accuracy.

\section{Study outcome measures}

The primary outcome measure will be reception staff response to unannounced simulated patient telephone calls. Primary Care staff will be graded on whether or not they correctly direct simulated patients for appropriate management. In addition, the associations between the nature of the telephone call, practice demographics and the subsequent response of the receptionist will be investigated.

The secondary outcomes will be:

1. Identifying GP receptionists' knowledge of stroke via questionnaire.

2. An understanding of Primary Care staff perceptions of stroke, the role of reception staff and attitudes towards training, through a series of qualitative interviews and focus groups.

\section{Sample size}

Sixty GPs will be recruited and data will be collected from a total of 600 unannounced simulated patient telephone calls. It is difficult to predict what proportion of patients would be expected to be correctly referred to hospital, as previous research is limited. A study by Mosley et al. [24], suggested that $55 \%$ of stroke patients were correctly referred by GP staff for immediate treatment. Given that the study assessment will be more rigorous, this proportion may be lower. Based on a conservative estimate that $50 \%$ of simulated patients will be correctly referred for immediate treatment and that each practice will receive 10 telephone calls over the study period (600 calls in total), an expected accuracy level would be to within $\pm 4 \%$ ( $50 \%$ [ $95 \%$ CI $46 \%$ to $54 \%]$ ). This calculation is based on the recruitment of one quarter of practices from the study area (60 out of 233 practices).

Questionnaire data will be collected from approximately 240 reception staff (assuming that each recruited 
practice has an average of four reception staff) and answerphone messages will be recorded in all participating practices (60 practices).

Qualitative data will be collected for up to 25 face-toface in-depth interviews with a variety of Primary Care staff and up to 10 reception staff focus groups.

\section{Data analysis}

\section{Unannounced simulated patient telephone calls}

Each unannounced simulated patient telephone call will be graded on the receptionist's response, specifically whether they correctly direct patients to an emergency ambulance or transfer the patient's call for immediate telephone assessment by a clinical member of the team. Logistic regression analysis will be used to investigate associations between correct referral of simulated patients, practice demographics (list size/number of receptionists) and the nature of unannounced simulated patient telephone call (e.g. perceived difficulty of detecting stroke, e. g. easy, moderately easy and difficult to recognise).

\section{Questionnaire}

Descriptive statistics will be used to describe the proportion of receptionists with each level of stroke symptom knowledge and the adequacy of planned responses to those symptoms. The association between stroke-related knowledge, planned responses and other demographic characteristics of GP receptionists (e.g. receptionist experience, age, gender, ethnicity, level of education and prior experience of stroke) will be examined using logistic regression analyses.

\section{Answerphone message assessment}

The content of messages and categories of referral advice, with a particular interest in the signs and symptoms they suggest require emergency action. Descriptive statistics will be used to outline content and suggested actions.

\section{Qualitative}

The qualitative component will follow the unannounced simulated telephone calls. The simulated call results will be fed into the conduct of the qualitative component, for example they may highlight areas that need further explanation to get a deeper picture [38]. Qualitative analysis will be performed using a framework approach [39]. This approach will allow the inclusion of $a$ priori knowledge and specific objectives in the analysis and it is especially relevant to the development of practice based applications. Relevant theory will be considered. To maximise the efficacy and validity of the framework approach all members of the research team including GP receptionist representative will have the opportunity to contribute to its development. NVivo will be used to manage the data. Group comparisons will be made across the interview and focus group data sets to themes unique to particular staff groups in addition to those that are shared. Validation will be achieved using the constant comparison method and by triangulation between themes identified by study team members and where possible between study branches (e.g. questionnaire and results of unannounced simulated patient telephone call study). Study team members have a diverse background of disciplines and experience.

\section{Ethical considerations}

Ethical approval has been obtained from the West of Scotland Research Ethics Service (reference: 12/WS/ 0259). Site specific R\&D approval has been obtained from across Birmingham and Solihull Primary Care Providers.

\section{Discussion}

The results of the RECEPTS study Primary Care are important for design of Primary Care services. Given the unusual nature of the proposed methodology, particularly the unannounced simulated patient telephone calls, it is important to acknowledge the potential problems involved in a study of this nature and how these might be avoided. Specifically:

1) There is a risk of reception staff recognising simulated patient records or unannounced simulated patient telephone calls. To reduce the chance of this happening: using multiple experienced role players, who have been trained by the Interactive Studies Unit, to conduct the telephone calls; having simulated patient records within the practice computer system so if the receptionist examines the clinical computer system for additional details the caller appears realistic; and conducting the calls over a period of time.

2) Concern that the unannounced simulated patient telephone calls will increase the burden of work for reception staff. To minimise this each practice will receive only 10 unannounced simulated patient telephone calls. Given the number of calls GPs receive per week (e.g. hundreds), an additional ten, with a maximum two minutes per call, over a three month period will not significantly impact their workload. GPs will be made aware of exactly how many unannounced simulated patient telephone calls to expect over the study period before they agree to participate.

3) The potential danger of inappropriate use of medical resources. To minimise this immediately following the unannounced simulated patient telephone call the GP receptionist, or whoever answered the call, 
will be informed that the telephone call was part of the study and thus no further action is needed.

4) Concern that receptionists will feel their performance is being examined. To reduce this our GP receptionist representative was involved in the design of study documentation, where the emphasis, particularly on the receptionist information cards is that this study is an opportunity to develop and improve training as well as patient care, not about testing. Furthermore, only whole study scores will be published - not individual practice or receptionist scores, so individuals will not be able to be criticised.

GP receptionists have a crucial role in patient referral, acting as gatekeepers to further care. It is important to gain an improved understanding of this role, how it plays out in the presentation of patients with serious conditions such as stroke and if there is a need for further training of reception staff in Primary Care. This study will provide this and also a valuable insight into the use of novel mixed methodologies which could have important implications for how health services are assessed in the future.

\section{Additional file}

Additional file 1: Example of an unannounced simulated patient telephone call data collection sheet.

\section{Abbreviations}

GP: General Practice; RECEPTS study: Receptionist rECognition and rEferral of Patients with Stroke Study; UK: United Kingdom.

\section{Competing interest}

The Stroke Association (charity) is a non-financial partner in this research, their role is to assist with disseminating of the findings after analysis and write up have been completed. However within their portfolio they provide GP receptionist training sessions. They will not be involved with the analysis or interpretation of the data so should not influence the results. All authors declare that they have no conflicts of interests.

\section{Authors' contributions}

RM, JS, SS, had the original idea. RM, JS, SS, developed the protocol with JJ, EB and RJM. CW \& JS advised on the simulation methodology and revised the protocol critically for intellectual content. All authors read and approved the final manuscript. RJM and RM gained the funding and RM is the guarantor.

\section{Acknowledgements}

Thank you to Jill Beech our GP receptionist representative. Thanks also to Interactive Studies Unit staff, for insight into conducting simulated patient studies, the participating members of the Interactive Studies Unit Simulated Patient Team, and to Norman Phillips, Christina Nand and Brin Helliwell for assistance in developing the vignettes.

This article presents independent research funded by the National Institute for Health Research (NIHR) through the Collaborations for Leadership in Applied Health Research and Care for Birmingham and Black Country (CLAHRC-BBC) programme. JS holds an MRC fellowship and RJM holds an NIHR professorship. The views expressed are those of the authors and not necessarily those of the NHS, the NIHR, MRC or the Department of Health.

\section{Author details}

${ }^{1}$ Department of Primary Care Health Sciences, University of Oxford, Oxford, UK. ${ }^{2}$ General Practitioner, Northfield Health Centre (Tudor Practice), Birmingham, UK. ${ }^{3}$ Primary Care Clinical Sciences, University of Birmingham, Birmingham, UK.

Received: 20 September 2013 Accepted: 7 May 2014

Published: 12 May 2014

\section{References}

1. Arber $S$, Sawyer $L$ : The role of the receptionist in general practice: a 'dragon behind the desk'? Soc Sci Med 1985, 20:911-921.

2. Gallagher M, Pearson P, Drinkwater C, Guy J: Managing patient demand: a qualitative study of appointment making in general practice. $\mathrm{Br} J \mathrm{Gen}$ Pract 2001, 51:280-285.

3. Arber S: What is a good GP? BMJ 1987, 294:287-288.

4. Copeman JP, Van Zwanenberg TD: Practice receptionists: poorly trained and taken for granted? Br J Gen Pract 1988, 38:14-16.

5. Carnegie MA, Gomel MK, Saunders JB, Britt H, Burns L: General practice receptionists' attitudes and beliefs towards preventive medicine before and after training and support interventions. Fam Pract 1996, 13:504-510.

6. Eisner $\mathrm{M}$, Britten $\mathrm{N}$ : What do general practice receptionists think and feel about their work? Br J Gen Pract 1999, 49:103-106.

7. Hammond J, Gravenhorst K, Funnell E, Beatty S, Hibbert D, Lamb J, Burroughs H, Kovandzic M, Gabbay M, Dowrick C, Gask L, Waheed W, Chew-Graham CA: Slaying the dragon myth: an ethnographic study of receptionists in UK general practice. Br J Gen Pract 2013, 63:e177-e184.

8. Townsend N, Wickramasinghe K, Bhatnagar P, Smolina K, Nichols M, Leal J, Luengo-Fernandez R, Rayner M: Coronary Heart Disease Statistics. 2012th edition. London: British Heart Foundation; 2012.

9. Saka O, McGuire A, Wolfe C: Cost of stroke in the United Kingdom. Age Ageing 2009, 38:27-32.

10. Wahlgren N, Ahmed N, Davalos A, Hacke W, Millan M, Muir K, Roine RO, Toni D, Lees KR: Thrombolysis with alteplase 3-4.5 h after acute ischaemic stroke (SITS-ISTR): an observational study. Lancet 2008, 372:1303-1309.

11. Saver JL: Time is brain - quantified. Stroke 2006, 37:263-266.

12. Araujo DV, Teich V, Passos RB, Martins SC: Analysis of the costeffectiveness of thrombolysis with alteplase in stroke. Ara Bras Cardiol 2010, 95:12-20.

13. Sandercock P, Wardlaw JM, Lindley RI, Dennis M, Cohen G, Murray G, Innes K, Venables G, Czlonkowska A, Kobayashi A, Ricci S, Murray V, Berge E, Slot KB, Hankey GJ, Correia M, Peeters A, Matz K, Lyrer P, Gubitz G, Phillips SJ, Arauz A: The benefits and harms of intravenous thrombolysis with recombinant tissue plasminogen activator within $6 \mathrm{~h}$ of acute ischaemic stroke (the third international stroke trial [IST-3]): a randomised controlled trial. Lancet 2012, 379:2352-2363.

14. Wardlaw JM, Murray V, Berge E, del Zoppo G, Sandercock P, Lindley RL, Cohen G: Recombinant tissue plasminogen activator for acute ischaemic stroke: an updated systematic review and meta-analysis. Lancet 2012, 379:2364-2372.

15. Henssge U, Hoffman A, Kavanagh S, Roughton M, Rudd A, Cloud G, On behalf of the Intercollegiate Stroke Working Party: The National Sentinal Stroke Audit 2010. Round 2011, 7:1-74. Ref Type: Report.

16. Nasr DM, Brinjikji W, Cloft HJ, Rabinstein AA: Utilization of intravenous thrombolysis is increasing in the United States. Int J Stroke 2012. 8(8):681-688.

17. Harraf F, Sharma AK, Brown MM, Lees KR, Vass RI, Kalra L: A multicentre observational study of presentation and early assessment of acute stroke. BMJ 2002, 325:17-22.

18. Lindsberg PJ, Happola O, Kallela M, Valanne L, Kuisma M, Kaste M: Door to thrombolysis: ER reorganization and reduced delays to acute stroke treatment. Neurology 2006, 67:334-336.

19. Lecouturier J, Murtagh MJ, Thomson RG, Ford GA, White M, Eccles M, Rodgers $\mathrm{H}$ : Response to symptoms of stroke in the UK: a systematic review. BMC Health Serv Res 2010, 10:157.

20. Jones SP, Jenkinson AJ, Leathley MJ, Watkins CL: Stroke knowledge and awareness: an integrative review of the evidence. Age Ageing 2010, 39:11-22.

21. Jones SP, Dickinson HA, Ford GA, Gibson JM, Leathley MJ, McAdam JJ, McLoughlin A, Quinn T, Watkins CL: Callers' experiences of making 
emergency calls at the onset of acute stroke: a qualitative study. Emerg Med J 2012, 29:502-505.

22. Mackintosh JE, Murtagh MJ, Rodgers H, Thomson RG, Ford GA, White M: Why people do, or do not, immediately contact emergency medical services following the onset of acute stroke: qualitative interview study. PLoS One 2012, 7:e46124.

23. Moloczij N, McPherson KM, Smith JF, Kayes NM: Help seeking at the time of stroke: stroke survivors perspectives on their decisions. Health Soc Care Community 2008, 16:501-510.

24. Mosley I, Nicol M, Donnan G, Dewey H: Family physician decisions following stroke symptom onset and delay times to ambulance call. BMC Fam Pract 2011, 12:82.

25. Jarrell B, Davis SM, Coyner J, Crocco T, Whiteman C: Primary care office responses to a stroke scenario. W V Med J 2011, 107(24):26-28.

26. Beullens J, Rethans JJ, Goedhuys J, Buntinx F: The use of standardized patients in research in general practice. Fam Pract 1997, 14:58-62.

27. Grant C, Nicolas R, Moore L, Salisbury C: An observational study comparing quality of care in walk-in centres with general practice and NHS direct using standardised patients. BMJ 2002, 324:1556.

28. Campbell JL, Carter M, Davey A, Roberts MJ, Elliott MN, Roland M: Accessing primary care: a simulated patient study. Br J Gen Pract 2013, 63:e171-e176.

29. Clarke CE, Edwards J, Nicholl DJ, Sivaguru A, Davies P, Wiskin C: Ability of a nurse specialist to diagnose simple headache disorders compared with consultant neurologists. J Neurol Neurosurg Psychiatry 2005, 76:1170-1172.

30. Watson MC, Skelton JR, Bond CM, Croft P, Wiskin CM, Grimshaw JM, Mollison J: Simulated patients in the community pharmacy setting. Using simulated patients to measure practice in the community pharmacy setting. Pharm World Sci 2004, 26:32-37.

31. Giesen P, Ferwerda R, Tijssen R, Mokkink H, Drijver R, van den Bosch W, Grol R. Safety of telephone triage in general practitioner cooperatives: do triage nurses correctly estimate urgency? Qual Saf Health Care 2007, 16:181-184.

32. Huibers $L$, Giesen $P$, Smits M, Mokkink H, Grol R, Wensing M: Nurse telephone triage in Dutch out-of-hours primary care: the relation between history taking and urgency estimation. Eur J Emerg Med 2012, 19:309-315.

33. Blades LL, Oser CS, Dietrich DW, Okon NJ, Rodriguez DV, Burnett AM, Russell JA, Allen MJ, Fogle CC, Helgerson SD, Gohdes D, Harwell TS: Rural community knowledge of stroke warning signs and risk factors. Prev Chronic Dis 2005, 2:A14.

34. Hickey A, Holly D, McGee H, Conroy R, Shelley E: Knowledge of stroke risk factors and warning signs in Ireland: development and application of the Stroke Awareness Questionnaire (SAQ). Int J Stroke 2012, 7:298-306.

35. Pancioli AM, Broderick J, Kothari R, Brott T, Tuchfarber A, Miller R, Khoury J, Jauch E: Public perception of stroke warning signs and knowledge of potential risk factors. JAMA 1998, 279:1288-1292.

36. Parahoo K, Thompson K, Cooper M, Stringer M, Ennis E, McCollam P: Stroke: awareness of the signs, symptoms and risk factors-a population-based survey. Cerebrovasc Dis 2003, 16:134-140.

37. Yoon SS, Heller RF, Levi C, Wiggers J, Fitzgerald PE: Knowledge of stroke risk factors, warning symptoms, and treatment among an Australian urban population. Stroke 2001, 32:1926-1930.

38. Richie J: The application of qualitative methods to social research In Qualitative Research Practice: A guide for social science students and researchers. Edited by Richie J, Lewis J. London: SAGE; 2003:24-46.

39. Ritchie J, Spenser L, O'Connor W: Carrying out qualitative analysis. In Qualitative Research Practice: A guide for social science students and researchers. Edited by Ritchie J, Lewis J. London: SAGE; 2003:219-262.

doi:10.1186/1471-2296-15-91

Cite this article as: Sheppard et al:: Receptionist rECognition and rEferral of PaTients with Stroke (RECEPTS) study - protocol of a mixed methods study. BMC Family Practice 2014 15:91.

\section{Submit your next manuscript to BioMed Central and take full advantage of:}

- Convenient online submission

- Thorough peer review

- No space constraints or color figure charges

- Immediate publication on acceptance

- Inclusion in PubMed, CAS, Scopus and Google Scholar

- Research which is freely available for redistribution

Submit your manuscript at www.biomedcentral.com/submit
C Biomed Central 